\title{
Book Review 'Troubled Child Training Techniques: A Practical Guide for Parents and Careers' (Malay Version)
}

\section{Uqbah lqbal*}

School of History, Politics and Strategy, Faculty of Social Sciences and Humanities, UKM 43650, BangiSelangor, Malaysia

Written by Dato' Dr Hasan Hj Mohd Ali, this book worked out at the request of many parents who are faced with the ills of troubled children. Educating and raising children is recognized is the most difficult task in this world. Moreover, the child shows behaviors and temperament far away from the usual norms. Fighting talk, skipping school, lying, lazy praying, lazy learning is among the things that often occur among children. Treatments like this are really disturbing when it is found that the behavior and temperament into practice in their children. This book view and analyze more deeply about the problems of this troubled children. The types of problems, causes and also educate their combined techniques to help parents understand the phenomenon of problem child this more clearly. Experts in the field of family education also agreed that there is no specific formula that can solve all the problems of discipline children. They are a unique family while they are different from each other. Therefore discipline strategies that are effective against a child may not bring the same results when applied to a child of the other.

Ongoing guidance and effective discipline is a major focus on the development of the children themselves. It will establish a feeling of self and dignity in them. Things such as insults, vilification of the parent or guardian will make these children have negative views of individuals around them. The child will learn and get used to the negative atmosphere that ultimately gave a bad impression in their behaviors. Process plant self-discipline of children is a challenging task. It requires patience, attention, cooperation and a good understanding of children. But the only inventory held by most parents is to emulate the experience of their own parents and how they educate children. Sometimes the experience of the past is not very effective because the situation at the time to be so different to the situation like today's increasingly challenging and demanding full commitment from parents. Parents at this age need to utilize as much time to their children. Putting the blame on others, such as teachers and the school is very unusual if the parents themselves do not take the path that should be to curb these troubled children. Misconduct children are difficult and impossible to be eliminated entirely. They have a high desire for one thing and very creative and like to try. They also like to do the one thing that is beyond the expectations of parents to cause problems. Parents must identify the causes and factors that led them to be so problematic.

There are some big changes that occurred from the point of today's lifestyle. These changes have an impact and a very large impact on the effectiveness of discipline as well as our role as parents. The economic situation also impacted the family. Parents had to go out to work to meet the demands of life. They returned in the late afternoon in a state of exhaustion. Children are increasingly burdened with a variety of tasks. In addition to school, there are a variety of activities, extra classes, school programs should be accompanied. Breaks for them almost nothing more especially for a child who does not know how to juggle. Parents and their children are in a stressful situation. Children also want a little freedom but parents are very worried about the possibility of the freedom given to them will cause problems. If you wish to be a successful parent then you should know how to discipline children at this age. Parents need a lot of training. Not because they are not good and so on but the task of educating children is no longer a simple matter.

*Corresponding author: Iqbal U, School of History, Politics and Strategy, Faculty of Social Sciences and Humanities, UKM 43650, BangiSelangor, Malaysia, Tel: +60389215555; E-mail: uqbah@siswa.ukm.edu.my

Received September 03, 2016; Accepted September 25, 2016; Published October 03, 2016

Citation: Iqbal U (2016) Book Review 'Troubled Child Training Techniques: A Practical Guide for Parents and Careers' (Malay Version). Intel Prop Rights. S1: 002. doi: 10.4172/2375-4516.S1-002

Copyright: (C) 2016 Iqbal U. This is an open-access article distributed under the terms of the Creative Commons Attribution License, which permits unrestricted use, distribution, and reproduction in any medium, provided the original author and source are credited. 